\title{
Nurminatalajikkeiden siementen muodostuksen erot
}

\author{
Matti Kousa ja Pirjo Mäkelä
}

Soveltavan biologian laitos, PL 27,00014 Helsingin yliopisto, email: matti.kousa@helsinki.fi ja pirjo.makela@helsinki.fi

\section{Tiivistelmä}

Nurminataa käytetään pääasiallisesti rehunurmien siemenseoksissa. Se onkin toiseksi eniten viljelty rehunurmikasvi timotein jälkeen. Nurminata on nopeakasvuinen, kestää toistuvaa niittämistä lyhyeen sänkeen ja on kilpailukykyinen. Sen rehulaatu ei kuitenkaan ole timotein luokkaa, minkä lisäksi se ei menesty hiekkaisilla mailla ja on arka kuivuudelle. Nurmirehun tuotannossa kotimaista, mieluiten paikallista alkuperää, olevan kylvösiemenen käyttö on suositeltavaa. Paikallisesti tuotettu kylvösiemen edesauttaa mm. kasvuston talvehtimista ja sadontuottokykyä. Nurminadan siemensadot ovat havaintojen mukaan laskeneet viimeisten kymmenen vuoden kuluessa. Tässä tutkimuksessa selvitettiin vanhan ja uuden nurminatalajikkeen satokomponenttien muodostumisessa esiintyviä eroja ja niiden selityskykyä siemensadolle. Tutkimuksessa käytettiin vanhaa, Kalevi, ja uutta, Fure, nurminatalajiketta. Määritimme nurminadoista niiden biomassan muodostuksen toisena kasvukautena toistuvin mittauksin, sadon osatekijät (mm. korsien, lehtien ja röyhyjen massat, versojen röyhyjen ja siementen lukumäärät sekä kukkien, tähkylöiden ja siementen muodostuksen) ja siemensadon. Lisäksi kasvustoista analysoitiin rehulaatu kahdesti (mm. D-arvo, raakaproteiini, kuiva-aine ja tuhka). Tulosten perusteella Fure muodostaa lehtevämmän kasvuston kuin Kalevi. Vaikka Kalevin kokonaisversomäärä on suurempi kuin Furen, Fure muodostaa Kalevia enemmän vegetatiivisia versoja ja sen biomassasta suurempi osa on lehdissä kuin Kalevilla. Fure muodostaa myös Kalevia enemmän tähkylöitä, kukkia ja siemeniä röyhyä kohden. Lajikkeiden siemensadossa ei silti ollut merkittävää eroa, joten ne pystyvät tehokkaasti kompensoimaan satokomponenteissa tapahtuvia muutoksia kuten viljat. Röyhyjen määrän lisääntyminen laski Kalevin siemensatoa samoin kuin siementen määrän lisääntyminen röyhyssä Furella. Biomassan lisääntyminen korrenkasvuvaiheen alussa vähensi Furen siemensatoa ja lisäsi Kalevin siemensatoa. Lajikkeiden rehulaadussa ei havaittu muita eroja kuin se, että Kalevin D-arvo pysyi pitempään korkeampana kuin Furen.

Asiasanat: nurminata, rehulaatu, sadonmuodostus, siementuotanto 


\section{Johdanto}

Nurminataa viljellään pääasiassa rehuksi. Alle viiden vuoden ikäisiä rehunurmia viljeltiin Suomessa vuonna 2005 noin 612000 hehtaarin alalla (TIKE 2005). Sitä, kuinka suurella osalla alasta kasvoi nurminataa, ei tiedetä. Nurmirehun tuotannossa kotimaista, mieluiten paikallista alkuperää olevan kylvösiemenen käyttö on suositeltavaa. Paikallisesti tuotettu kylvösiemen edesauttaa mm. kasvuston talvehtimista ja sadontuottokykyä. Vuonna 2004 Suomessa viljeltiinkin nurminataa siemeneksi 1594 hehtaarin alalla. Kasvinjalostuksessa on keskitytty kuitenkin pääasiallisesti rehulaadun ja -määrän parantamiseen, jolloin samalla on saatettu joutua tinkimään siemensadosta.

Niemeläisen ja Niskasen (2003) mukaan nurminata on Suomessa toiseksi eniten viljelty rehunurmikasvi timotein jälkeen. Rehuntuotannossa nurminadalla on monia hyviä ominaisuuksia (Havstad 1998). Se lähtee nopeasti kasvamaan niiton jälkeen, mistä johtuen se soveltuu hyvin seoksiin niin laitumissa kuin säilörehunurmissakin. Nurminata kestää tiheää niittämistä lyhyeen sänkeen ja intensiivistä laidunnusta paremmin kuin timotei. Pitkäikäisillä laitumilla ja niityillä nurminata on myös kilpailukykyisempi kuin timotei. Se ei kuitenkaan ole yhtä nopeakasvuinen kuin koiranheinä tai englanninraiheinä (Havstad 1998). Nurminata on arka kuivuudelle ja menestyy siksi heikosti hiekkaisilla mailla. Nurminadasta voidaan tehdä myös heinää, mutta sen kuiva-ainesato ja laatu eivät kuitenkaan ole timotein veroisia. Laidunkäytössä nurminata ei ole aivan yhtä maittavaa kuin timotei tai englanninraiheinä. Tämä johtuu nurminadan nopeasta kasvusta, minkä seurauksena siitä tulee nopeasti liian karkeaa ja kuituista laiduntavien eläinten makuun (Havstad 1998). Nurminataa käytetään seoksissa joko pelkästään timotein kanssa tai timotein ja ruokonadan, englanninraiheinän tai puna-apilan kanssa.

Nurminadan siemensadon määrää kasvuston siementuotantopotentiaali sekä sen toteutuminen. Siementuotantopotentiaalin määrittävät kukkivien versojen määrä, röyhyjen koko sekä fertiilien kukkien määrä. Potentiaalin toteutumisen taas määrää siemeniä muodostavien kukkien osuus sekä tuhannen siemenen paino. Näihin tekijöihin vaikuttavat suoraan tai epäsuorasti mm. seuraavat tekijät: kasvin korkeus, lehtiala, kuiva-ainesato, kukkimisajankohta, korren lujuus ja siementen varisemisherkkyys (Fang ym. 2004). Monivuotisten heinäkasvien siemensadon muodostuminen alkaa jo edellisenä loppukesänä ja syksynä heti edellisen sadonkorjuun jälkeen. Nurminadalla suurin osa siemensatoa tuottavista versoista muodostuu edellisen loppukesän ja syksyn aikana (Hare 1994, Havstad 1996, Havstad ym. 2004).

Monet lauhkean vyöhykkeen heinät mukaan lukien nurminata vaativat kukkiakseen niin sanotun kaksoisinduktion. Kaksoisinduktio on kasvin tehokas sopeutumiskeino ympäristöönsä. Kukinnan induktiossa kasvullinen eli vegetatiivinen verso muuttuu röyhyä muodostavaksi eli generatiiviseksi versoksi. Induktion ensimmäisessä vaiheessa eli primaari-induktiossa ei muodostu vielä kukka-aiheita, vaan verso valmistautuu sekundaari-induktioon. Primaari-induktio vaatii tapahtuakseen lyhyen päivän ja matalan lämpötilan. Tämä tapahtuu yleensä syksyn ja talven kuluessa. Sekundaari-induktiossa muodostuvat kukka-aiheet, joista kehittyy sekundaari-induktion jälkeen nopeasti kukintoja. Sekundaariinduktio vaatii pitkän päivän ja primaari-induktiota korkeamman lämpötilan, joten se tapahtuu yleensä keväällä (Heide 1994). Induktio tapahtuu kasvin ja verson iästä riippumatta, kun olot ovat induktiolle suotuisat. Induktion alkaminen ei riipu myöskään kasvin lehtialasta vaan ennemminkin kasvin iästä (Havstad 1996). Myös induktioperiodin jälkeen esiin tuleva verso voi kukkia, mutta tällöin verso on indusoitunut induktioperiodin aikana ollessaan vielä silmuasteella näkymättömissä. Kukkivia versoja voi tulla esiin vielä myöhään syksyllä ja keväälläkin, mutta käytännössä suurimman osan sadosta tuottavat kuitenkin loppukesällä ja syksyllä muodostuneet versot (Havstad 1996, Havstad ym. 2004).

Tämän tutkimuksen tarkoituksena oli selvittää, onko eri nurminatalajikkeiden välillä eroa siementen muodostuksessa riippuen niiden kauppaanlaskuajasta.

\section{Aineisto ja menetelmät}

Koe toteutettiin Helsingin yliopiston Viikin opetus- ja tutkimustilalla. Nurminatalajikkeiksi valittiin Fure (1999) ja Kalevi (1979) niiden kauppaanlaskuvuoden perusteella. Koe järjestettiin täydellisesti satunnaistettuna kokeena neljällä kerranteella ruutukoon ollessa $10 \mathrm{~m}^{2}$. Kenttäkoe perustettiin keväällä 2005 suojaviljaan (ohra). Suojaviljan kylvötiheys oli 500 itävää siementä/ $\mathrm{m}^{2}$. Nurminadan kylvömäärä oli $30 \mathrm{~kg} / \mathrm{ha}$. Koe lannoitettiin perustamisvuonna Pellon Y3-lannoitteella [N-P-K: 21-3-9 (Kemira Growhow Oyj, Helsinki)] $380 \mathrm{~kg} \mathrm{ha}^{-1}$. Oljet kerättiin puinnin jälkeen pois ruuduilta. Keväällä 2006 koe lannoitettiin Suomensalpietarilla [N-P-K: 26-0-1 (Kemira Growhow Oyj, Helsinki)] $385 \mathrm{~kg} \mathrm{ha}^{-1}$. 
Kasvustojen biomassan kertymistä seurattiin neljänä ajankohtana (ensimmäisen kerran pensomisvaiheen lopussa korren kasvun jo alettua ja tämän jälkeen kahden viikon välein) kerätyin $30 \mathrm{~cm}$ kaistaleiden avulla. Näytteitä kuivattiin $80{ }^{\circ} \mathrm{C}$ lämpötilassa kahden vuorokauden ajan ja punnittiin.

Rehuanalyysiä varten kerättiin näytteitä kahtena eri ajankohtana. Ensimmäinen näytteenottoajankohta määritettiin Artturi®-verkkopalvelun D-arvo ennusteen avulla. Ensimmäinen rehunäyte otettiin, kun D-arvoennuste oli $69 \%$ ja toinen, kun D-arvoennusteen arvo oli $67 \%$ kolme vuorokautta myöhemmin. Näytteeksi leikattiin $30 \mathrm{~cm}$ kaistale noin $5 \mathrm{~cm}$ korkeudelta maasta kolmesta kohdasta ruutua. Näytteistä analysoitiin primaarinen ja sekundaarinen kuiva-aine, tuhkapitoisuus, raakaproteiinipitoisuus ja D-arvo. Primaarinen kuiva-aine määritettiin kuivaamalla näytteitä $105{ }^{\circ} \mathrm{C}$ lämpötilassa 20 tunnin ajan. Sekundaarinen kuiva-aine määritettiin kuivaamalla näytteitä $105^{\circ} \mathrm{C}$ lämpötilassa 16 tunnin ajan. Typpipitoisuus määritettiin Kjeldahlin (menetelmä 984.13. AOAC, 1990) menetelmällä. D-arvo määritettiin matemaattisesti (Huhtanen ym. 2006) orgaanisen aineksen in vitro liukoisuudesta (Nousiainen ym. 2003).

Kukkien lukumäärä laskettiin röyhyjen ollessa kokonaan näkyvillä ja kasvuston alkaessa kukkia. Näytteeksi kerättiin kaksi $10 \mathrm{~cm}$ kaistaletta ruudulta. Kukat laskettiin haaroittain ja fertiilit ja steriilit kukat eroteltiin määrittämällä emin ja heteiden kehitys. Lisäksi näytteistä laskettiin röyhyjen lukumäärä. Tähkylöiden massan kertymisen seuraamiseksi kerättiin kasvustonäytteitä kahdeksana eri ajankohtana röyhyjen tultua näkyviin aina varisemisvaiheeseen asti parin päivän välein. Näytteeksi kerättiin $10 \mathrm{~cm}$ kaistale kahdesta kohdasta ruutua. Tähkylät eroteltiin haaroittain, kuivattiin $80{ }^{\circ} \mathrm{C}$ lämpötilassa kahden vuorokauden ajan ja punnittiin.

Tuleentumisvaiheessa kasvustosta kerättiin ruuduittain kolme 30x30 cm näytettä $5 \mathrm{~cm}$ maan pinnan yläpuolelta. Näytteistä määritettiin korsien, lehtien, röyhyjen ja siementen massat erikseen sekä versojen, röyhyjen ja siementen lukumäärä. Korret, lehdet ja röyhyt eroteltiin, niitä kuivattiin $80{ }^{\circ} \mathrm{C}$ lämpötilassa kahden vuorokauden ajan ja ne punnittiin. Punnituksen jälkeen röyhyistä irrotettiin siemenet, jotka punnittiin ja niiden lukumäärä laskettiin. Tuleentunut sato puitiin, kuivattiin ja lajiteltiin. Sadosta määritettiin 1000 siemenen paino sekä itävyys.

Tulokset analysoitiin varianssianalyysillä SAS 9.14-ohjelmistolla (proc glm), minkä lisäksi tehtiin korrelaatioanalyysi (proc corr) ja askeltava regressioanalyysi (proc stepwise).

\section{Tulokset ja tulosten tarkastelu}

Kummankin lajikkeen siemensadot (Kalevi $876 \mathrm{~kg} \mathrm{ha}^{-1}$, Fure $747 \mathrm{~kg} \mathrm{ha}^{-1}$ ) olivat selvästi korkeampia kuin mitä Suomen keskisato, $462 \mathrm{~kg} \mathrm{ha}^{-1}$, oli vuosina 1983 - 2006 (Valtion siementarkastuslaitos 1990 ja 1994, EVIRA 2007). Ne eivät kuitenkaan eronneet toisistaan. Furella oli enemmän vegetatiivisia versoja kuin Kalevilla. Kalevin versoista keskimäärin $56 \%$ oli röyhyllisiä, kun Furen versoista vain 45 $\%$ oli röyhyllisiä (Taulukko 1). Heinäkasveille on tyypillistä generatiivisessa vaiheessa olevien versojen nopea biomassan lisääntyminen voimakkaasta korren kasvusta johtuen. Vegetatiiviset versot kasvattavat biomassaa generatiivisia versoja hitaammin. Furen Kalevia suuremmasta vegetatiivisten versojen määrästä johtuen Furen biomassa lisääntyi hitaammin kuin Kalevin.

Taulukko 1. Satokomponentit, siemensato ja siementen itävyys Fure- ja Kalevi-nurminadoilla.

\begin{tabular}{|c|c|c|}
\hline Ominaisuus & Fure & Kalevi \\
\hline Versojen lukumäärä, $\mathrm{kpl} \mathrm{m}^{-2}$ & $2238 \pm 59^{\mathrm{a}}$ & $2655 \pm 92^{* *}$ \\
\hline Röyhyjen lukumäärä, $\mathrm{kpl} \mathrm{m}^{-2}$ & $1007 \pm 74^{\mathrm{a}}$ & $1485 \pm 66^{* * *}$ \\
\hline Siementen lukumäärä, $\mathrm{kpl} \mathrm{m}^{-2}$ & $77796 \pm 5082^{a}$ & $94188 \pm 4848^{*}$ \\
\hline Siemeniä röyhyä kohti, kpl & $77 \pm 4^{\mathrm{b}}$ & $63 \pm 3^{*}$ \\
\hline Tuhannen siemenen paino, $g$ & $1,96 \pm 0,06^{\mathrm{a}}$ & $2,10 \pm 0,01^{* * *}$ \\
\hline Siementen itävyys, $\%$ & $85,3 \pm 1,7^{\mathrm{a}}$ & $83,6 \pm 2,1$ \\
\hline Siemensato, $\mathrm{kg} \mathrm{ha}^{-1}$ & $747 \pm 55^{b}$ & $876 \pm 33$ \\
\hline
\end{tabular}

Arvot ovat keskiarvoja $\pm \mathrm{SE}, \mathrm{n}^{\mathrm{a}}=12, \mathrm{n}^{\mathrm{b}}=4$.

Vaikka lajikkeilla ei ollut eroja korsien biomassassa tuleentumisvaiheessa, Furella oli kuitenkin enemmän lehtimassaa kuin Kalevilla (Kuva 1). Vastaavasti Kalevilla oli enemmän siemen- ja röyhy- 
massaa. Siten Fure näyttäisi pyrkivän muodostamaan Kalevia enemmän vegetatiivista eli rehuksi soveltuvaa biomassaa kuin Kalevi, joka puolestaan on pystykasvuisempi ja korsiintuvampi kuin Fure.

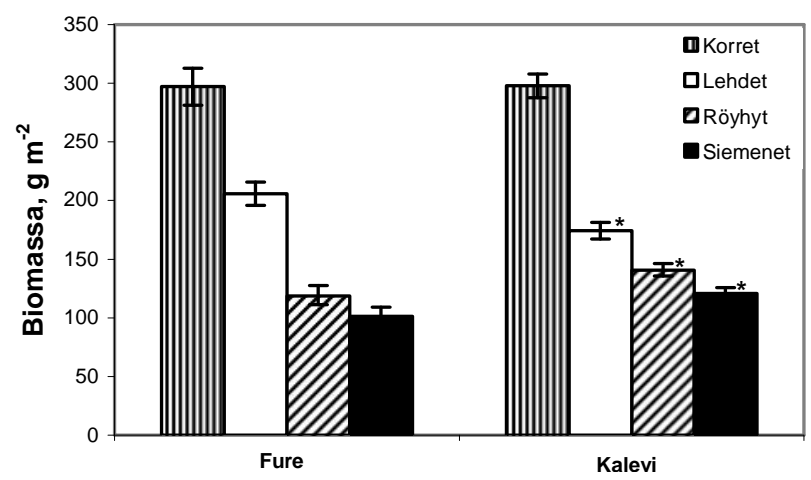

Kuva 1. Tuleentuneiden Fure- ja Kalevi-nurminatojen kuivamassan jakaantuminen korsiin, lehtiin, röyhyihin ja siemeniin. Pylväät kuvaavat keskiarvoa $\pm \mathrm{SE}, \mathrm{n}=12$.

Versojen, röyhyjen ja siementen lukumäärissä oli lajikkeiden välillä merkitsevä ero indikoiden satokomponenttien vaikutusta sadon määrään. Fure muodosti merkitsevästi enemmän kukkia röyhyä kohden (141) kuin Kalevi (113). Samoin Fure muodosti huomattavasti enemmän siemeniä röyhyä kohden kuin Kalevi, vaikkakin Kalevilla niitä oli alaa kohden enemmän johtuen suuremmasta röyhyllisten versojen määrästä (Taulukko 1). Lisäksi on huomioitava, että Kalevin 1000 siemenen paino oli korkeampi kuin Furen. Näyttäisikin siltä, että samoin kuin viljat myös nurminata pystyy kompensoimaan siemensatoa satokomponenteissa tapahtuvin muutoksin. Askeltavan regressioanalyysin perusteella röyhyjen määrän lisääntyminen Kalevilla näyttäisi vähentävän siemensatoa samoin kuin siementen määrän lisääntyminen röyhyssä Furella (Taulukko 2). Biomassan lisääntyminen korrenkasvun alussa lisäsi Kalevin siemensatoa, mutta vähensi Furen siemensatoa. Siementen lisääntyminen röyhyssä lisää röyhyssä esiintyvää siementen välistä kilpailua hiiliyhdisteistä samoin kuin röyhyjen määrän lisääntyminen lisää kilpailua hiiliyhdisteistä versojen välillä.

Rehuarvoissa ei ensimmäisellä näytteenottokerralla ollut eroja lajikkeiden välillä. Furen Darvo oli $699 \mathrm{~g} \mathrm{~kg}^{-1} \mathrm{ka}$ ja Kalevin $696 \mathrm{~g} \mathrm{~kg}^{-1} \mathrm{ka}$. Kalevin D-arvo kuitenkin pysyi pidempään korkeampana kuin Furen samoin kuin Kalevin primaarinen kuiva-ainepitoisuus (25\%). Furen vuotuinen säilörehusato on kuitenkin Kalevia suurempi virallisissa lajikekokeissa (Kangas ym. 2002), mikä voi selittyä tässäkin kokeessa havaitulla Furen Kalevia suuremmalla lehtevyydellä.

Taulukko 2. Siemensatoa $\left(\mathrm{kg} \mathrm{ha}^{-1}\right)$ selittävät tekijät askeltavalla regressioanalyysillä.

\begin{tabular}{lllrlrrr}
\hline \hline Lajike & Vakio & I selittävä tekijä & \multicolumn{1}{c}{$\mathrm{R}^{2}$} & II selittävä tekijä & $\mathrm{R}^{2}$ \\
\hline Fure & 1487,07 & Biomassa, $\mathrm{g} \mathrm{m}^{-2}$ & $-2,01$ & 0,9843 & Röyhyn sato, g & $-1291,92$ & 0,9975 \\
Kalevi & 3340,43 & Biomassa, g m & & 1,27 & 0,5814 & Röyhyjä, kpl m & \\
\hline \hline
\end{tabular}

Biomassa = biomassa korren kasvun alussa

Röyhyjen $1 \mathrm{~km}$ = röyhyjen määrä tuleentuneessa kasvustossa

Röyhyn sato = siementen massa röyhyä kohden

\section{Johtopäätökset}

Nurminatalajikkeiden välillä merkittävimmät erot siementen muodostuksessa olivat niiden vegetatiivisten ja generatiivisten versojen määrässä, uudemman lajikkeen - Furen - tuottaessa enemmän vegetatiivisia versoja. Tällöin röyhyjä muodostui pinta-alaa ja kasvia kohti vähemmän. Fure muodosti kuitenkin enemmän kukkia röyhyä kohden, jolla se pystyi kompensoimaan generatiivisten versojen määrää. Satokomponentteja kompensoimalla lajikkeet pystyivät tuottamaan lähes saman sadon. Myöskään niiden rehulaadussa ei ollut selviä eroja, vaikkakin Kalevin rehulaatu näytti säilyvän pidempään korkeana. Fure oli kuitenkin lehtevämpi kuin Kalevi.

\section{Kirjallisuus}

EVIRA. 2007. Siementuotannon vuosivaihtelut 1989 - 2006. 
Fang, C., Aamlid, T.S., Jørgense, Ø. \& Rognli, O.A. 2004. Phenotypic and genotypic variation in seed production traits within a full-sib family of meadow fescue. Plant Breeding 123: 241-246.

Hare, M.D. 1994. Effect of vernalisation and tiller age on seed production in tall fescue. J. Appl. Seed Prod. 12: 77-82.

Havstad, L.T. 1996. Juvenility and flowering in Festuca pratensis Huds. 1. Effects of plant age, cultivar and duration of primary induction treatments. Norwegian J. Agric. Sci. 10: 159-178.

Havstad, L.T. 1998. Seed yield of meadow fescue (Festuca pratensis Huds.) in Norway and Denmark: The effects of locations, cultivars and autumn management. Acta Agric. Scand., Sect. B, Soil \& Plant Sci. 48: 144158.

Havstad, L.T., Aamlid, T.S., Heide, O.M. \&Junttila, O. 2004. Transfer of flower induction stimuli to nonexposed tillers in a selection of temperate grasses. Acta Agric. Scand., Sect. B, Soil \& Plant Sci. 54: 23-30.

Heide, O.M. 1994. Control of flowering and reproduction in temperate grasses. New Phytol. 128: 347-362.

Huhtanen, P., Nousiainen, J. \& Rinne, M. 2006. Recent developments in forage evaluation with special reference to practical applications. Agric. Food Sci. 15: 293-323.

Kangas A., Laine A., Niskanen M., Salo Y., Vuorinen M., Jauhiainen L. \& Mäkelä L. 2002. Virallisten lajikekokeiden tulokset 1994-2001 MTT:n selvityksiä 2. Jokioinen: Maa- ja elintarviketalouden tutkimuskeskus. $282 \mathrm{~s}$.

Niemeläinen, O.\& Niskanen, M. 2003. Tuloksia ulkomaisten nurmikasvilajikkeiden siementuotantokyvystä Suomessa. Teoksessa (toim.) O. Niemeläinen, M. Topi-Hulmi. Nurmisiementen tuotanto vientiin tutkimus- ja kehityshankkeen päätösseminaari. Suomen Nurmiyhdistyksen julk. 20: 8-31.

Nousiainen, J., Rinne, M., Hellämäki, M., \& Huhtanen, P. 2003. Prediction of the digestibility of the primary growth of grass silages harvested at different stages of maturity from chemical composition and pepsin-cellulase solubility. Animal Feed Sci. Technol. 103: 97-111.

TIKE. 2005. Käytössä oleva maatalousmaa 2005. Maa- ja metsätalousministeriön tietopalvelukeskus. Valtion siementarkastuslaitos. 1990. Valtion siementarkastuslaitos 1.7.1983-30.6.1988. Helsinki. 98 s. Valtion siementarkastuslaitos. 1994. Valtion siementarkastuslaitos Kasvintuotannon tarkastuskeskus Siementarkastusosasto 1.7.1988-30.6.1993. Loimaa. $90 \mathrm{~s}$. 